\title{
Biomechanical in vitro evaluation of three stable internal fixation techniques used in sagittal osteotomy of the mandibular ramus: a study in sheep mandibles
}

\author{
Leandro Benetti de OLIVERA', Eduardo SANT'ANA², Antonio José MANZATO³ , Fábio Luis Bunemer GUERRA4, G. \\ William ARNETT ${ }^{5}$ \\ 1- DDS, MSc, Undergraduate student, Oral and Maxillofacial Program, Universidade do Sagrado Coração, Bauru, SP, Brazil. \\ 2- DDS, PhD, Associated Professor, Oral and Maxillofacial Surgery, Bauru School of Dentistry, University of São Paulo, Bauru, SP, Brazil. \\ 3- MSc, PhD, Associated Professor, Univ. Estadual Paulista - UNESP, São José do Rio Preto, SP, Brazil. \\ 4- DDS, MSc, Oral and Maxilofacial Surgeon, Private Practice, São José do Rio Preto, SP, Brazil. \\ 5- DDS, PhD, F.A.C.D. Maxillofacial Surgery, Santa Barbara, CA, USA
}

Corresponding address: Rua Antonio Fernandes Billar, 301 - Jardim Alto Rio Preto - 15020-290 - São José do Rio Preto, - SP - Brasil -Phone: +55 17 32333073/8129-2946 - e-mail: le_benetti@yahoo.com.br

Received: October 6, 2010 - Modification: September 1, 2011 - Accepted: September 30, 2011

\section{ABSTRACT}

\begin{abstract}
A mong the osteotomies performed in orthognathic surgery, the sagittal osteotomy of the mandibular ramus (SOMR) is the most common, allowing a great range of movements and stable internal fixation (SIF), therefore eliminating the need of maxillomandibular block in the postoperative period. Objectives: The purpose of this study was to evaluate the biomechanical resistance of three national systems used for SIF in SOMR in sheep mandibles. Material and methods: The study was performed in 30 sheep hemi-mandibles randomly divided into 3 experimental groups, each containing 10 hemi-mandibles. The samples were measured to avoid discrepancies and then subjected to SOMR with 5-mm advancement. In group I, $2.0 \times 12 \mathrm{~mm}$ screws were used for fixation, inserted in an inverted "L" pattern (inverted "L" group). In group II, fixation was performed with two $2.0 \times 12 \mathrm{~mm}$ screws, positioned in a linear pattern and a 4-hole straight miniplate and four $2.0 \times 6.0 \mathrm{~mm}$ monocortical screws (hybrid group). In group III, fixation was performed with two 4-hole straight miniplates and eight $2.0 \times 6.0 \mathrm{~mm}$ monocortical screws (mini plate group). All materials used for SIF were supplied by Osteosin - SIN. The hemimandibles were subjected to vertical linear load test by Kratos K2000MP mechanical testing unit for loading registration and displacement. Results: All groups showed similar resistance during mechanical test for loading and displacement, with no statistically significant differences between groups according to analysis of variance. Conclusion: These results indicate that the three techniques of fixation are equally effective for clinical fixation of SOMR.
\end{abstract}

Key words: Mandible. Osteotomy. Bone plates. Bone screws.

\section{INTRODUCTION}

Sagittal osteotomy of the mandibular ramus (SOMR) is certainly one of the most performed surgical procedures in orthognathic surgery. The versatility provided by its outlining offers a wide contact between the osteotomized segments, promoting better repair and stability, as well as allowing a precise and adequate application of the concept of stable internal fixation.
Several studies have shown that the SOMR can be fixed by means of plates and/or inter fragmentary screws, with good results both in vitro ${ }^{12,23}$ and in patients ${ }^{19,31}$. Stable internal fixation (SIF) is a method that enables the stabilization of the osteotomized segments through screws or metallic plates. This type of fixation is put directly in contact with the bone structure, allowing its function during the bone repair ${ }^{8}$. Moreover, it eliminates or reduces the application of the maxillomandibular block, 
resulting in a greater benefit for the patient due to its stability and biomechanical properties superior to the methods previously used ${ }^{7,8,26}$. SIF of sagittal osteotomy can be made only by screws, being these compressive or positional ${ }^{5,35}$, monocortical plates ${ }^{19}$ or a combination of both techniques ${ }^{20}$. These techniques differ according to the size, number, pattern and type of material used $13,26,35$, as well as some variations regarding its angularity and tool management ${ }^{21,32}$. All of them tend to explain which techniques present better SIF, providing greater stabilization between the bone segments and lower morbidity ${ }^{28}$.

The first sagittal osteotomy in which SIF was used was described by Spiess/25 (1976), using compressive screws. However, this technique has a major disadvantage, which is, the torque of the condylar segment, altering its position. The use of positional screws was introduced by Souyris ${ }^{24}$ (1978), in which the screw engages in the two cortical plates, keeping the planned space between the segments and promoting the system stabilization in a passive way, resulting in smaller condylar torque and lesion of the inferior alveolar nerve ${ }^{3,36}$.

In cases of great mandibular advancement or asymmetrical movements of the mandible, however, there is a decrease between the bone contact of the distal and proximal segments of the osteotomy, leading to a difficulty in the installation of the bicortical screws ${ }^{4}$. This lack of contact can be solved through the accomplishment of compensatory wear and tear in both segments or through bone grafts. Nevertheless, many times, due to the magnitude of the movement, there is the need of altering the fixation technique, using monocortical screws and plates. In addition to allowing the fixation in great advancements, this technique has other advantages such as lower rates of lesion to the neurovascular bundle and smaller torques to the proximal segment ${ }^{29}$.

Tulasne and Schendel ${ }^{30}$ (1989) recommended the use of one or two plates combined with 2.0 $\mathrm{mm}$ monocortical screws. Those authors reported that there is a lower risk of injury to the inferior alveolar nerve directly or through the compression among the segments. After the maxillomandibular blockage, having the proximal segment already positioned, the space of the lateral cortical is measured and the plates of appropriate size are selected. One or two plates could be used on each side, depending on the required stability, direction and degree of mandibular displacement and the type of miniplate to be used.

Advantages of using miniplates and monocortical screws include easier execution of the technique; easier correction of inadequate positioning of the proximal segment; easier removal of miniplates under local anesthesia; no need of skin incisions; plate folding for adaptation to the outline of the osteotomized segments; and smaller risk of injury to the inferior alveolar nerve ${ }^{26}$.

Foley and Beckman ${ }^{9}$ (1992) compared the rigidity of three groups of SIF performed in 12 sheep mandibles with sagittal osteotomy. The groups were GI (three 2.0-mm bicortical positional screws in an inverted "L"-pattern), GII (one miniplate with four 2.0-mm monocortical screws) and GIII (three 2.7-mm bicortical screws, in a linear pattern). The osteotomies fixed with miniplates and inverted " $L$ " screws were more resistant than those fixed with linear screws. The flaws in the miniplate group were caused mainly by plate deformation rather than by flaws at the bone-screw interface.

Shetty, et al.22 (1996) compared several patterns of three miniplate systems [doubled plates (3D), titanium meshes and conventional plates] combining some groups of plates with a positional bicortical screw in the retromolar space and comparing them with the standard technique of three 2.4$\mathrm{mm}$ positional screws in a linear pattern. After the loading test, the authors concluded that the groups fixed by miniplates and positional screws had superior stability when compared with the groups that were fixed exclusively with miniplates or with positional linear screws.

The in vitro bending strength of SIF with absorbable and metallic screws in SOMR in sheep hemi-mandibles has been evaluated ${ }^{11}$. The screws were inserted as lag screws, with an inverted " $L$ " configuration, and the set was submitted to bending strength tests. The groups showed no statistically significant differences, indicating the feasibility of both for osteosynthesis in SOMR.

Peterson, et al. ${ }^{18}$ (2005) evaluated the mechanical resistance of polyurethane mandibles subjected to SOMR and a $5 \mathrm{~mm}$ advancement, testing four types of fixation: fixation with three bicortical screws in inverted " $L$ " pattern, straight miniplate with 4 monocortical screws, curved miniplate with 6 monocortical screws and adjustable miniplate with 4 monocortical screws. All plates and screws belonged to the system $2.0 \mathrm{~mm}$. The authors concluded that bicortical screws in inverted " $L$ " pattern presented superior resistance than the other fixations using plates and monocortical screws.

Van Sickels, et al. ${ }^{33}$ (2005) evaluated the mechanical behavior in 7-mm advancements of polyurethane mandibles, using different groups of fixations. In group I, fixation was accomplished with an adjustable miniplate and 4 monocortical screws; group II used an adjustable miniplate with 4 monocortical screws and a positional screw; group III used an adjustable miniplate with 4 monocortical screws and 2 positional screws; group IV used an adjustable miniplate with 4 monocortical screws and 3 positional screws; in group $\mathrm{V}$, fixation was 
performed with 3 bicortical screws in an inverted "L" position. The authors concluded that the addition of bicortical screws to the system improved the mechanical stability and that only after the placement of 2 or 3 screws (group III and IV) the vertical forces became similar to the forces of the inverted "L" group.

Ozden, et al. ${ }^{16}$ (2006) have used fresh mandibles of sheep subjected to SOMR and compared the stability of 10 fixation types. The authors concluded that the groups of bicortical screws in the inverted "L" pattern promote greater mechanical stability. In the group where miniplates were used, the one put obliquely and fixed with 2 bicortical screws in the proximal segment was the most rigid in the group of miniplates.

A recent case report ${ }^{17}$ described the technique of hybrid fixation with monocortical screws and plates combined with two bicortical screws in SOMR in the movement of advancement and counterclockwise rotation. In a follow-up of 14 months, the authors reported the patient's satisfaction as for the treatment, without alterations in dental roots and regression of the paresthesia of the inferior alveolar nerve. They have concluded that this fixation type increases the stability of the fixation without significant risks to the temporomandibular joint and to the inferior alveolar nerve.

In spite of some controversies, the literature demonstrates the viability of the use of plates and monocortical screws in the fixation of SOMR. However, few works report the mechanical resistance of the materials of national origin in both fixation forms in the situation of mandibular advancement. Therefore, the aim of this study was to perform an in vitro comparison of the mechanical resistance of three national systems used for SIF in SOMR in sheep mandibles.

\section{MATERIAL AND METHODS}

This study was approved by the Ethics Committee in Research of Sagrado Coração University (USC) under the protocol number 041/09.

Mandibles of adult sheep aged 1 year to 1 year and a half were obtained in slaughterhouses from the region of São José do Rio Preto, SP, Brazil. The mandibles were separated from the heads after total dissection of the soft tissues and, after that, they were split up in the mandibular symphysis, generating 60 hemi-mandibles. Only the 30 hemimandibles corresponding to the right side were used in this study. The specimens were measured (height and width of the ramus, length of the mandible and distance between the anterior limit of the foramen and the anterior border of the mandible) (Figure 1 ) because the use of mandibles of disproportional sizes could interfere in the mechanical test. The attribution of the units to the experimental groups was performed by random distribution, constituting a balanced experiment with a probabilistic sample of ten units in each experimental group. Soon afterwards, the selected experimental units were stored frozen until the beginning of the experiment.

The hemi-mandibles received SOMR, with adaptations in the drawing, according to the anatomy of the sheep ${ }^{9,16}$. As soon as the separation was completed and the removal of bone interferences or dental roots that could inhibit a good adaptation of the osteotomized parts was performed, the distal segment was advanced in $5 \mathrm{~mm}$ and fixations were applied in three different ways (Figure 2). All materials used for SIF were supplied by Osteosin SIN Sistema de Implante Nacional Ltda., Fixadores, São Paulo, SP, Brazil.

In Group I (inverted "L"), in order to fixate the osteotomy, three self-tapping screws of $2.0 \times 12$ $\mathrm{mm}$ were used (PBM 2012), in a positional pattern. After the positioning of the segments, by using a drill of a $1.5 \mathrm{~mm}$ diameter, both the cortical plates were perforated in an angle of $90^{\circ}$, under abundant irrigation of water to avoid thermal damage to the bone. The length of the screw was determined to cross both cortical plates and to surpass at least $1 \mathrm{~mm}$ of the internal cortical. The disposition of

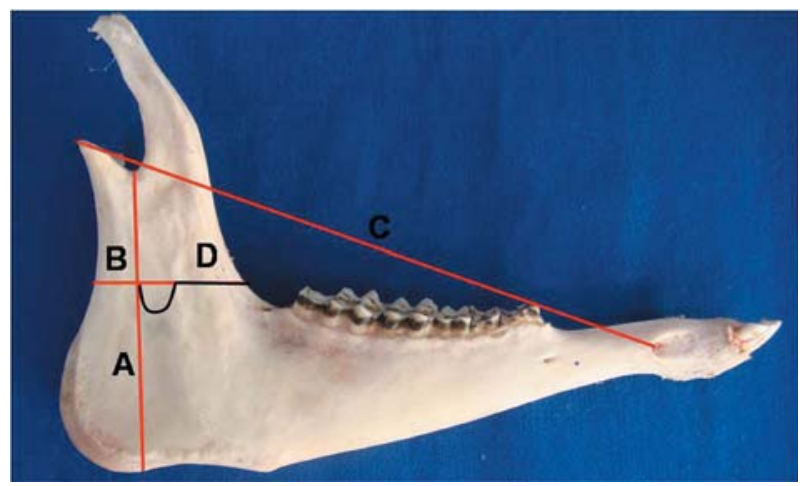

Figure 1- Mandible measures: $(A)$ height of the ramus; (B) width of the ramus; (C) length of the mandible, (D) Distance between the anterior limit of the foramen and the mandible ramus

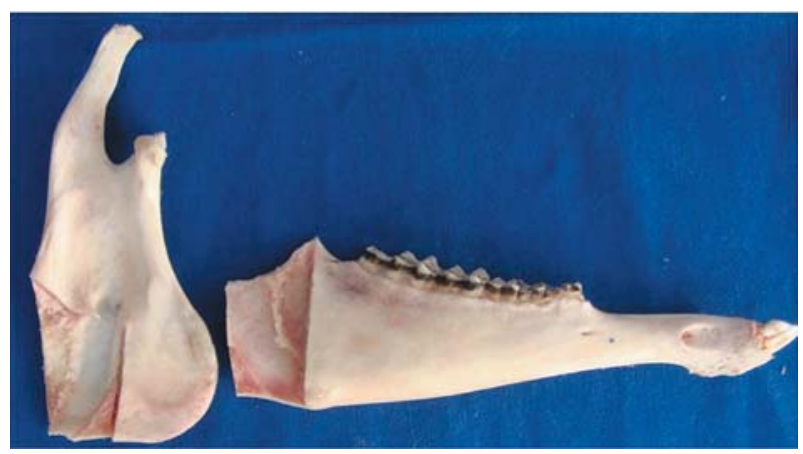

Figure 2- Sagittal osteotomy used to separate the segments 
the screws was tripoidal, with two screws in the superior border (tension area) and one in the inferior border (compression area), installed uprightly to the cortical bone. The distance among the screws of the superior border was of approximately $10 \mathrm{~mm}$, being applied in the areas of better contact among the cortical plates. The inferior screws were installed approximately $10 \mathrm{~mm}$ above the inferior border, in places where the cortical plates presented larger thickness and where there was a good contact area among the same ones (Figure 3).

In Group II (hybrid group), in order to fixate the osteotomy, a plate (PI 201004P) was applied in the neutral area, and four self-tapping monocortical screws of $2.0 \times 6 \mathrm{~mm}$, were put uprightly to the bone. Two of these screws were installed in the distal segment and the other two in the proximal segment. The distance between the plate and the superior border was approximately $20 \mathrm{~mm}$. After the fixation of the plate, two self-tapping screws of $2.0 \times 12 \mathrm{~mm}$ were positioned in linear disposition, being the first installed approximately $10 \mathrm{~mm}$ from the superior border and the second $5 \mathrm{~mm}$ from the first one, keeping the same height (Figure 4).

In Group III (plates group), in order to fixate the osteotomy, two plates (PI 201004P) were applied in the neutral area and tension area, and eight self-tapping monocortical screws of $2.0 \times 6 \mathrm{~mm}$, were installed uprightly to the bone, first in the distal segment and later in the proximal segment, keeping a distance of approximately $10 \mathrm{~mm}$ among the plates (Figure 5).

Once fixed, the hemi-mandibles were mounted in a block of colorless chemically activated acrylic resin (Jet; Artigos Odontológicos Clássico Ltda, São Paulo, SP, Brazil), including the posterior border and the mandibular condyle, but without allowing contact of the resin with the distal segment, avoiding bonding of this segment. This assembly was performed by putting the resin in the sandy phase, in a wax mold and positioning the hemi-mandible until final polymerization. The mold allowed the standardization of the dimensions of all the pieces, facilitating their fixation to a U-shaped device, with 3 lateral screws on each side, welded vertically on a central base that was fixed in the testing machine. This way, it was possible to maintain a parallelism between the oclusal plan and the horizontal plan of the machine.

In order to perform the mechanical test, after inclusion in the resin block, the mandibles were tied to a steel support and afterwards fixed to the basis of mechanical test device. In the headstock of the testing machine, a force sensor was fixed, denominated "load cell" of $50 \mathrm{kgf}$. The machine was programmed to record the maximum resistance force, in kgf, exhibited by the system regarding a progressive load, at a displacement speed of $1 \mathrm{~mm} / \mathrm{s}$.

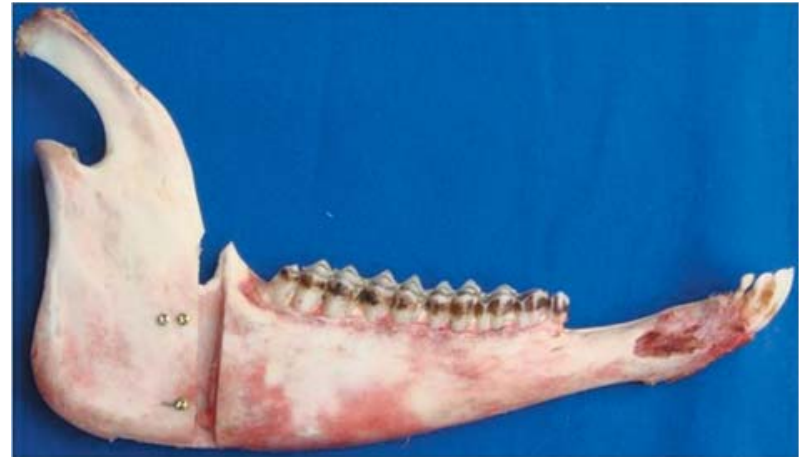

Figure 3- Inverted “L” group (Group I)

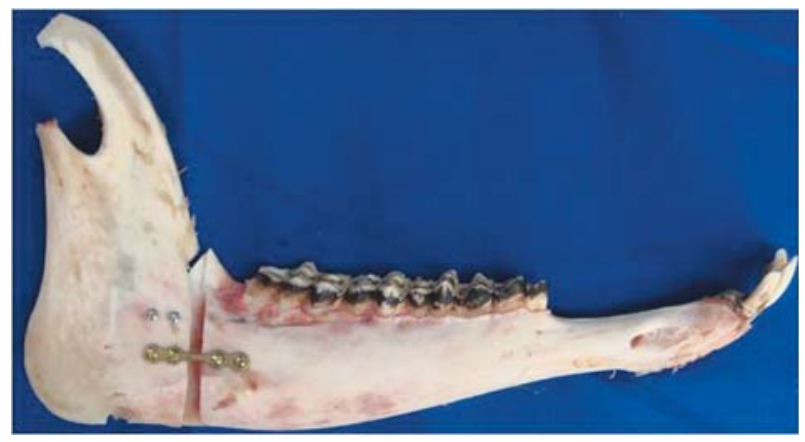

Figure 4- Hybrid group (Group II)

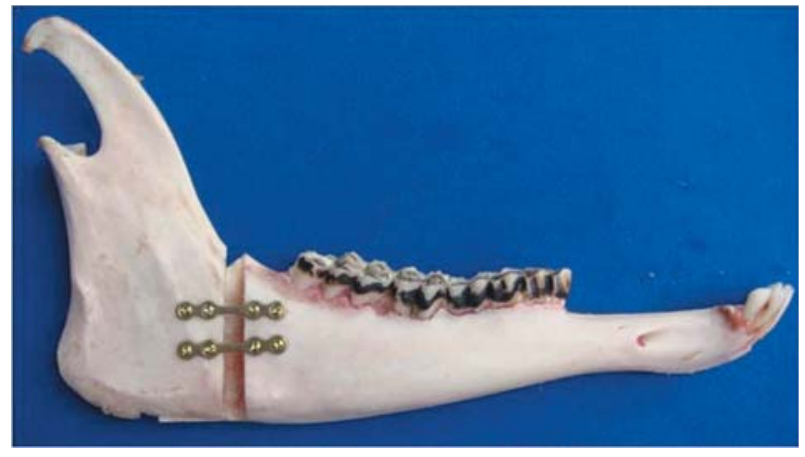

Figure 5- Plates group (Group III)

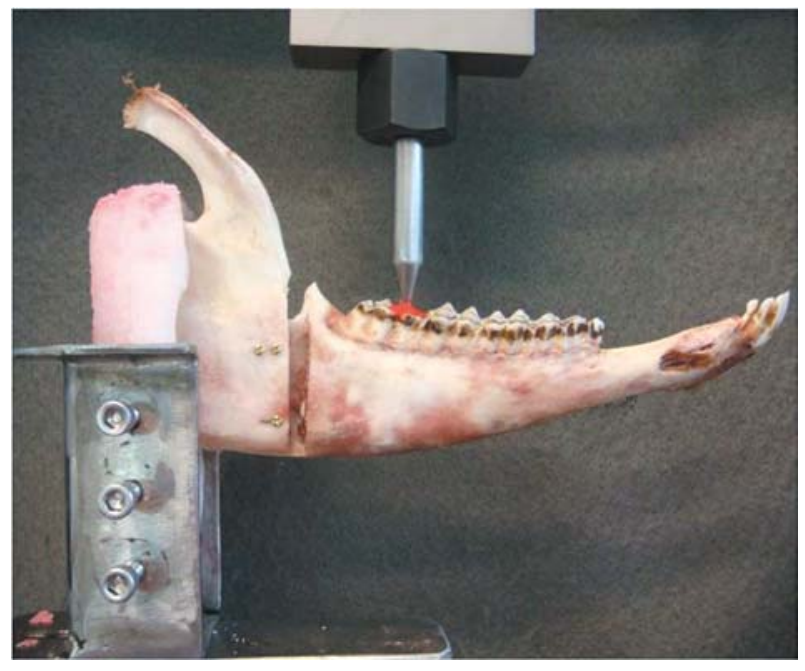

Figure 6- Mandible fixed to the support and positioned in the KRATOS K2000MP universal testing machine 
In order to test the sample, a vertical progressive force was applied in the area of the second molar until a flaw was observed in the fixation or a fracture was observed in the hemi-mandible. In the area of application of force, a resin support was done so that the force cell could not slip and generate a mistake during the test (Figures 6 and 7).

The data were transmitted to a computer that

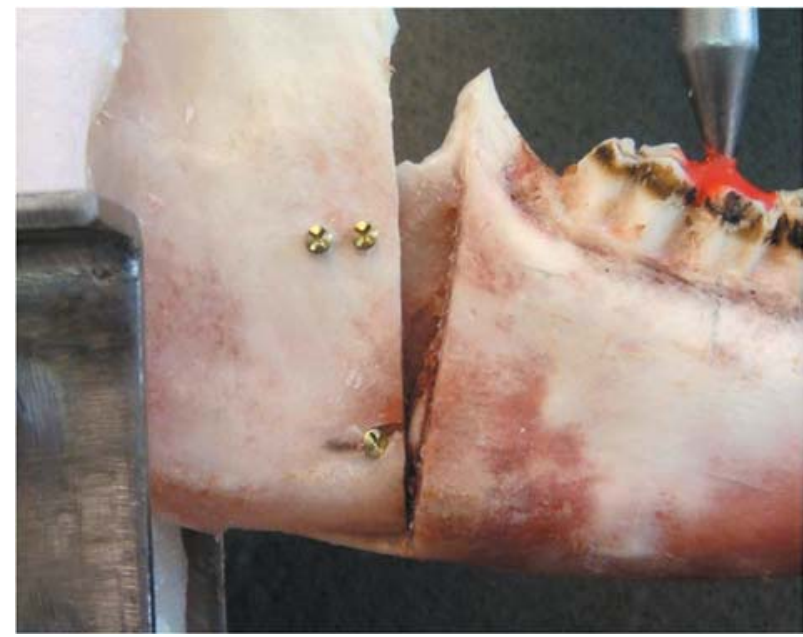

Figure 7- Fracture of the mandible after the application of force

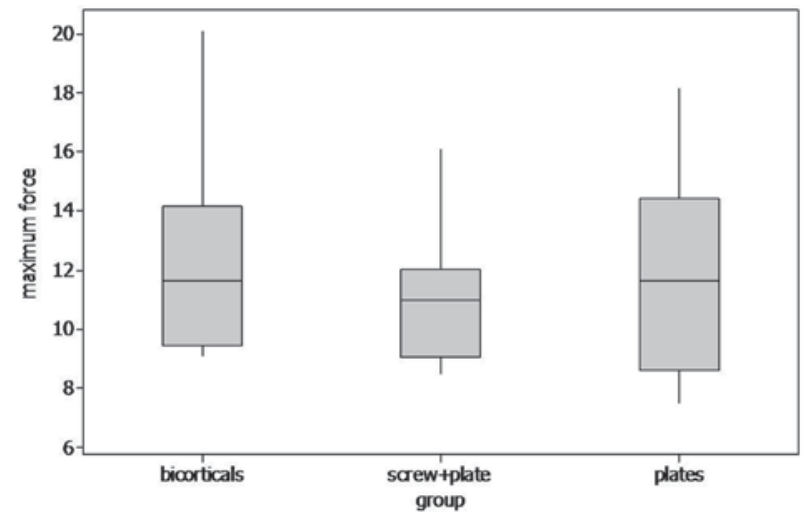

Figure 8- "Boxplot" graphic regarding maximum force for Groups I (Inverted "L"), II (Hybrid) and III (Plates), respectively generated a data spreadsheet of force versus displacement. The flaw in the fixation was verified by the displacement of the headstock of the testing machine, being arbitrarily considered a flaw when there was a displacement larger than $8 \mathrm{~mm}$ from the headstock of the machine or from the fracture of the mandible.

The data referring to the maximum force needed to bring instability and failure to the system were collected and subjected to statistical analysis by analysis of variance at a $95 \%$ confidence level to discover which group presented better mechanical stability.

\section{RESULTS}

The values obtained were organized in tables and individualized by groups. This allowed descriptive (Table 1) and comparative (Table 2) statistical analyses of data, enabling the interpretation of the resistance to displacement and maximum force in each group, considering as variables the different types of fixation (Figures 8 and 9).

Table 2 describes the treatment effects and the comparison among the three types of fixation in each variable. No statistically significant differences were found among the groups ( $p>0.05)$.

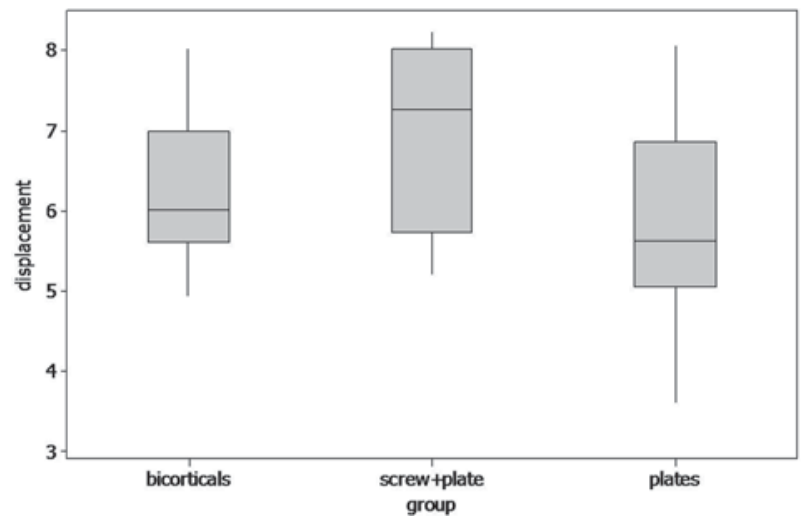

Figure 9- "Boxplot" graphic regarding displacement Groups I (Inverted "L"), II (Hybrid) and III (Plates), respectively

Table 1- Descriptive statistical analysis of maximum force (kgf) and displacement ( $\mathrm{mm}$ ) obtained in Groups I (Inverted "L"), II (Hybrid) and III (Plates)

\begin{tabular}{ccccccc}
\hline Variable & Treatment & avg. & s.d. & minimum & median & maximum \\
\hline \multirow{2}{*}{ Maximum force } & Bicorticals & 12.2 & 3.3 & 9.07 & 11.61 & 20.07 \\
& Screw+plate & 11 & 2.2 & 8.475 & 10.988 & 16.1 \\
& Plates & 11.8 & 3.3 & 7.5 & 11.62 & 18.13 \\
\cline { 2 - 6 } Displacement & Bicorticals & 6.29 & 0.93 & 4.94 & 6.01 & 8.03 \\
& Screw+plate & 6.97 & 1.1 & 5.22 & 7.26 & 8.23 \\
& Plates & 5.83 & 1.36 & 3.61 & 5.62 & 8.06 \\
\hline
\end{tabular}

Where: $\mathrm{x}$ - mean; s.d.- standard deviation 
Table 2- Values of the statistics $F$ and $P$, resulting from the application of ANOVA for statistical analysis of the variables: maximum force and displacement

\begin{tabular}{cccc}
\hline Variable & Statistic $\mathbf{F}$ & Value $\mathbf{P}$ & Conclusion \\
\hline Maximum force & 0.41 & 0.67 & There is no treatment effect \\
Displacement & 2.51 & 0.10 & There is no treatment effect \\
\hline
\end{tabular}

* Significant if $p<0.05$

\section{DISCUSSION}

This study evaluated the effects of three different types of fixation of SOMR in a sheep mandible model. The results obtained showed that all methods provided good stabilization of the mandible after the application of a mechanical test to evaluate maximum force and displacement of the segments.

Biomechanical studies in vitro are useful to evaluate the resistance of the fixation as well as the disposition of the materials of osteosynthesis before being used in humans. Nowadays, aiming at the standardization of tests, professionals are choosing to use resin models. However, in spite of the advantage of standardization, these models have the disadvantage of possessing modules of elasticity which are different from those of fresh bones, resulting in a problem that does not happen when fresh bones are used. Fresh bovine ribs are more frequently used because they are easier to obtain. However, they present an anatomy which is quite different than the mandible's anatomy, and this is the main fact that contraindicates its use in this specific type of test. The use of frozen fresh mandibles of animals is the best indication for these purposes ${ }^{9}$. Conservation of the pieces by freezing did not cause significant alterations in the biomechanical resistance of the bone during many months ${ }^{6}$.

The choice of working with fresh bones, as in the present study in which sheep mandibles were used, was due to the ease of obtaining and storage of samples and possibility of standardization and performing similar SOMR to those performed in humans. However, some modifications of the original technique had to be done to perform the surgery in an animal model, such as medial inclination of the cut and performing this cut below the mandibular foramen. Other advantages of the experimental model used in this study are: use of SIF, low cost and wide usage of fresh bone samples in literature $16,27,31,37$. It is important to emphasize that the data obtained from biomechanical studies using analogous bones cannot be directly transferred to the clinical use in humans, serving only as indicative parameters of the behavior of a certain technique and/or material.

The use of positional screws is the most recognized procedure for fixating sagittal osteotomies ${ }^{7}$. The disposition of positional screws in inverted " $\mathrm{L}$ ", where two screws are installed in the superior border and one in the inferior border below the mandibular canal, is the most cited form of fixation, showing the best mechanical resistance when compared with other fixation forms $2,9,10,22$. However, the use of monocortical screws and plates has become highly widespread in recent years, with good results $3,14,19,26,32,34$. The use of plates combined with bicortical screws has also been described $12,15-17,23,33$.

The literature emphasizes the superiority of the SIF with bicortical screws compared with the technique of fixation with a miniplate and four monocortical screws. Bouwman, et al. ${ }^{6}$ (1994) and Shetty, et al. ${ }^{23}$ (1996) have observed increased rigidity of the systems fixed with positional bicortical screws in linear pattern than those with a miniplate and four monocortical screws. In turn, the inverted " $L$ " pattern is the one that has been mostly compared with monocortical fixation techniques, whereas all studies employing this methodology suggested that fixation with bicortical screws results in greater resistance to displacement ${ }^{1,16,18}$.

Regarding the hybrid groups, it has been observed in vitro that the addition of a bicortical screw in the retromolar region substantially increases the capacity of stabilizing sagittal osteotomy in systems with miniplates and monocortical screws ${ }^{23}$. Moreover, the hybrid systems have demonstrated greater resistance than the systems with three bicortical screws in linear pattern.

Another hybrid alternative to enhance the biomechanical resistance of a system is the use of a 4-hole miniplate, whereas the two proximal holes receive bicortical screws and the two distal holes receive monocortical screws. Ozden, et al. ${ }^{16}$ (2006) reported that this technique was more resistant than the technique using miniplates and simply monocortical screws. This technique was though inferior to the method using three bicortical screws in inverted " $L$ " pattern. However, when another bicortical screw was added to the basilar and distal region of the proximal segment in the hybrid group, the results were similar to the group in inverted "L" pattern.

Clinically, it is difficult to measure the extent to which bone repair can be damaged by these differences of resistance among these three fixation 
techniques. Although in some clinical conditions, the surgeon will need to choose which type of fixation will offer the best post-operatory results. The type (advancement, rebound, or asymmetry) and amount of movement and the exact position between the proximal and distal segments can critically influence the degree of bone contact and the quality of the surface which will receive the fixation material.

The load peaks (maximum force) generated in some specimens during the bending test probably occurred due to the sudden reductions in biomechanical resistance of the system at some moment during load application, and this could have been the point of failure. In the other specimens, there was a progression of loading and displacement without the occurrence of peaks, so the final displacement $(8 \mathrm{~mm})$ was considered as the point of failure. One should consider, however, that an $8-\mathrm{mm}$ displacement is far in excess of the clinical and radiographic limit of what would be considered a failure of the fixation system. According to Ardary, et al. $^{2}$ (1989), this limit would be $1 \mathrm{~mm}$.

Some anatomical limitations, such as tooth position, location of the inferior alveolar nerve, thin alveolar walls after the extraction of third molars during sagittal osteotomy, minimum surface of overlapping between distal and proximal segments, or even incorrect fractures, can make the use of three bicortical screws impracticable. In other words, not always is the clinical situation favorable to the use of the most resistant technique. The results of this work indicate that the hybrid technique or the fixation with two miniplates and monocortical screws are good options regarding resistance to displacement, as effective as SIF.

\section{CONCLUSIONS}

According to the methodology proposed and to the obtained results, it can be concluded that fixations in inverted " $L$ " pattern, hybrid method with two bicortical screws and one miniplate or two miniplates with monocortical screws showed similar results when linear loading was applied.

\section{REFERENCES}

1- Anucul B, Waite PD, Lemons JE. In vitro strength analysis of sagittal split osteotomy fixation: noncompression monocortical plates versus bicortical position screws. J Oral Maxillofac Surg. 1992;50:1295-9.

2- Ardary WC, Tracy DJ, Brownridge GW 2 ${ }^{\text {nd }}$, Urata MM. Comparative evaluation of screw configuration on the stability of the sagittal split osteotomy. Oral Surg Oral Med Oral Pathol. 1989;68:125-9.

3- Assael LA. Stable internal fixation of osteotomies of the facial skeleton. In: Prein J, editor. Manual of internal fixation in the cranio-facial skeleton. Berlin: Springer; 1998. p. 185-98.
4- Bell WH. Rigid fixation of the Le Fort I and sagittal split ramus osteotomies. In: Yaremchuk MJ, Gruss JS, Manson PN. Rigid fixation of the craniomaxillofacial skeleton. Boston: ButterworthHeinemann; 1992. p. 423-50.

5- Blomqvist JE, Ahlborg G, Isaksson S, Svartz K. A comparison of skeletal stability after mandibular advancement and use of two rigid internal fixation techniques. J Oral Maxillofac Surg. 1997;55:568-74.

6- Bouwman JPB; Tuinzing DB, Kostense PJ. A comparative in vitro study on fixation of sagittal split osteotomies with Würzburg screws, Champy miniplates and Biofix (biodegradable) rods. Int J Oral Maxillofac Surg. 1994;23:46-8.

7- Ellis E 3rd. The internal fixation of fractures:historical perspectives. In: Tucker MR, Terry BC, White EP Jr, Van Sickle JE, editors. Rigid fixation for maxillofacial surgery. Philadelphia: Lippincott; 1991. p. 3-29.

8- Ellis E $3^{\text {rd }}$, Dean J. Rigid fixation of mandibular condyle fractures. Oral Surg Oral Med Oral Pathol. 1993;76:6-15.

9- Foley WL, Beckman TW. In vitro comparison of screw versus plate fixation in the sagittal split osteotomy. Int J Adult Orthodon Orthognath Surg. 1992; 7:147-51.

10- Foley WL, Frost DE, Paulin WB Jr, Tucker MR. Internal screw fixation: comparison of placement pattern and rigidity. J Oral Maxillofac Surg. 1989;47:720-3.

11- Gomes PP, Guimarães Filho R, Mazzonetto R. Evaluation of the bending strength of rigid internal fixation with absorbable and metallic screws in the mandibular ramus sagittal split osteotomy - in vitro study. Pesqui Odontol Bras. 2003;17:267-72.

12- Hammer B, Ettlin D, Rahn B, Prein J. Stabilization of the short sagittal split osteotomy: in vitro testing of different plate and screw configurations. J Craniomaxillofac Surg. 1995;23:321-4.

13- Lupori JP, Kewitt GF, Van Sickels JE. Bilateral sagittal split osteotomy advancement and setback. In: Fonseca RJ, editor. Oral and maxillofacial surgery. $3^{\text {rd }}$ ed. Philadelphia: W.B. Saunders; 2000. p. 297-310.

14- Michelet FX, Deymes J, Dessus B. Osteosynthesis with miniaturized screwed plates in maxillo-facial surgery. J Maxillofac Surg. 1973;1:79-84.

15- Murphy MT, Haug RH, Barber JE. An in vitro comparison of the mechanical characteristics of three sagittal ramus osteotomy fixation techniques. J Oral Maxillofac Surg. 1997;55:489-94.

16- Ozden B, Alkan A, Arici S, Erdem E. In vitro comparison of biomechanical characteristics of sagittal split osteotomy fixation techniques. Int J Oral Maxillofac Surg. 2006;35:837-41.

17- Pereira FL, Janson M, Sant'Ana E. Hybrid fixation in the bilateral sagittal split osteotomy for lower jaw advancement. J Appl Oral Sci. 2010;18:92-9.

18- Peterson GP, Haug RH, Van Sickels J. A biomechanical evaluation of bilateral sagittal ramus osteotomy fixation techniques. J Oral Maxillofac Surg. 2005;63:1317-24.

19- Rubens BC, Stoelinga PJ, Blijdorp PA, Schoenaers JH, Politis C. Skeletal stability following sagittal split osteotomy using monocortical miniplate internal fixation. Int J Oral Maxillofac Surg. 1988;17:371-6.

20- Schwartz HC, Relle RJ. Bicortical-monocortical fixation of the sagittal mandibular osteotomy. J Oral Maxillofac Surg. 1996;54:234-5.

21- Shepherd JP, Dohvoma CM, Harradine NW. Screw fixation after mandibular sagittal split osteotomy: an intra-oral approach. $\mathrm{Br}$ J Oral Maxillofac Surg. 1991;29:325-9.

22- Shetty V, Freymiller E, McBrearty D, Caputo AA. Experimental analysis of functional stability of sagittal split ramus osteotomies secured by miniplates and position screws. J Oral Maxillofac Surg. 1996;54:1317-24.

23- Shetty V, Freymiller E, McBrearty D, Caputo AA. Functional stability of sagittal split ramus osteotomies: effects of posicional screw size and placement configuration. J Oral Maxillofac Surg. 1996;54:601-9. 
24- Souyris F. Sagittal splitting and bicortical screw fixation of the ascending ramus. J Maxillofac Surg. 1978;6:198-203.

25- Spiessl B. Rigid internal fixation after sagittal split osteotomy of the ascending ramus. In: Spiessl B. New concepts in maxillofacial bone surgery. New York: Springer-Verlag; 1976. p. 115-22.

26- Stoelinga PJ, Borstlap WA. The fixation of sagittal split osteotomies with miniplates: the versatility of a technique. J Oral Maxillofac Surg. 2003;61:1471-6.

27- Suuronen R, Pohjonen T, Vasenius J, Vainionpää S. Comparison of absorbable self-reinforced multilayer poly-l-lactide and metallic plates for the fixation of mandibular body osteotomies: an experimental study in sheep. J Oral Maxillofac Surg. 1992;50:25562.

28- Tucker MR, Terry BC, White EP Jr, Van Sickle JE, editors. Rigid fixation for maxillofacial surgery. Philadelphia: Lippincott; 1991 29- Turvey TA, Hall DJ. Intraoral self-threading screw fixation for sagittal osteotomies: early experiences. Int J Adult Orthodon Orthognath Surg. $1986 ; 1: 243-50$.

30- Tuslane JF, Schendel SA. Transoral placement of rigid fixation following sagittal ramus split osteotomy. J Oral Maxillofac Surg. 1989;47:651-2.

31- Uckan S, Schwimmer A, Kummer F, Greenberg AM. Effect of the angle of the screw on the stability of the mandibular sagittal split ramus osteotomy: a study in sheep mandibles. $\mathrm{Br}$ J Oral Maxillofac Surg. 2001;39:266-8.
32- Ueki K, Nakagawa K, Takatsuka S, Yamamoto E. Plate fixation after mandibular osteotomy. Int J Oral Maxillofac Surg. 2001;30:490-6.

33- Van Sickels JE, Flanary CM. Stability associated with mandibular advancement treated by rigid osseous fixation. J Oral Maxillofac Surg. 1985;43:338-41.

34- Van Sickels JE, Peterson GP, Holms S, Haug RH. An in vitro comparison of an adjustable bone fixation system. J Oral Maxillofac Surg. 2005;63:1620-5.

35- Watzke IM, Tucker MR, Turvey TA. Lag screw versus position screw techniques for rigid internal fixation of sagittal osteotomies: a comparison of stability. Int J Adult Orthodon Orthognath Surg. 1991;6:19-27.

36- Watzke IM, Turvey TA, Phillips C, Proffit WR. Stability of mandibular advancement after sagittal osteotomy with screw or wire fixation: a comparative study. J Oral Maxillofac Surg. 1990;48:108-21.

37- Wittenberg JM, Wittenberg RH, Hipp JA. Biomechanical properties of resorbable poly-L-lactide plates and screws: a comparison with traditional systems. J Oral Maxillofac Surg. 1991;49:512-6. 